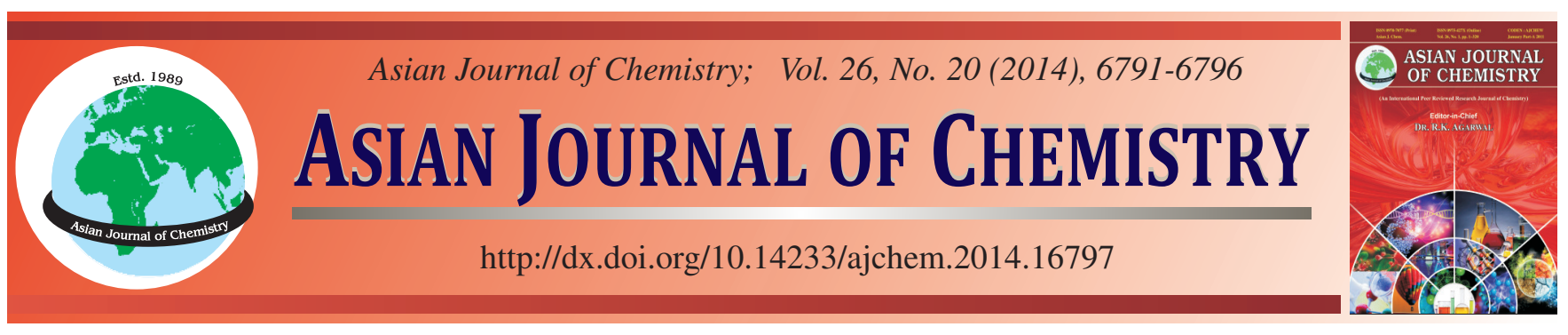

\title{
Vapor-Liquid Equilibrium Experiments for Di- $n$-propyl Ether and 1-Propanol Binary System at 1,013 and 300 mbar and Prediction of Equilibrium Experimental Data using Wilson, UNIQUAC and NRTL Models
}

\author{
Yu Mi KIm ${ }^{1}$, Sung Gook $\mathrm{OH}^{2}$, Dongsun $\mathrm{KIm}^{3}$ and Jungho $\mathrm{CHO}^{3, *}$
}

${ }^{1}$ Process Solution Team, Kumho Petrochemical R and BD Center, Daejeon, Republic of Korea

${ }^{2}$ School of Chemical Engineering, Sungkyunkwan University, Suwon, Republic of Korea

${ }^{3}$ Department of Chemical Engineering, Kongju National University, Cheonan, Republic of Korea

*Corresponding author: Fax: +82 41 5542640, Tel: +82 41 5219366; E-mail: jhcho@kongju.ac.kr

Received: 30 November 2013;

Accepted: 15 April 2014;

Published online: 25 September 2014;

AJC-16011

Herein, isobaric vapor-liquid phase equilibrium experiments for the binary mixture of di- $n$-propyl ether and 1-propanol were performed at 1,013 and 300 mbar, respectively. At 1,013 mbar, an azeotrope was formed where the mole composition of di- $n$-propyl ether is 0.6472 with azeotropic temperature of $90.18^{\circ} \mathrm{C}$. On the other hand, at $300 \mathrm{mbar}$, an azeotrope was formed with a mole composition of 0.7682 mole fraction of di- $n$-propyl ether and an azeotropic temperature of $52.61{ }^{\circ} \mathrm{C}$. Throughout these vapor-liquid phase equilibrium experiments, it was observed that the azeotropic point of the di- $n$-propyl ether/1-propanol binary system changes with the system pressure. By conducting a regression analysis of the binary vapor-liquid phase equilibrium experimental data using liquid activity coefficients thermodynamics (LACT) models, such as UNIQUAC, NRTL and Wilson embedded in PRO/II with PROVISION 9.1, a commercial chemical process simulator from Invensys, Inc., optimum binary interaction parameters for the individual model equations were determined. This work lead to the generation of binary interaction parameters that better fit the experimental data parameters embedded in the PRO/II simulator.

Keywords: Vapor-liquid equilibrium experiments, Di- $n$-propyl ether, 1-Propanol.

\section{INTRODUCTION}

Di- $n$-propyl ether is manufactured by reacting alcohols with sulfuric acid, as shown in eqn. 1 , where $\mathrm{X}$ signifies halogen.

\section{$\mathrm{CH}_{3} \mathrm{CH}_{2} \mathrm{CH}_{2} \mathrm{CO}^{-}+\mathrm{CH}_{3} \mathrm{CH}_{2} \mathrm{CH}_{2} \mathrm{X} \rightarrow$}

$\mathrm{CH}_{3} \mathrm{CH}_{2} \mathrm{CH}_{2} \mathrm{OCH}_{2} \mathrm{CH}_{2} \mathrm{CH}_{3}+\mathrm{X}$ (1)

$\mathrm{Di}-n$-propyl ether is widely used as a solvent because it dissolves most organic materials; it is also utilized as a soil insecticide and medical anesthetic ${ }^{1}$. Propanol can exists as either 1-propanol or 2-propanol isomers, according to the position of the hydroxyl functional group. 1-Propanol is prepared by the oxo reaction shown in eqn. 2. 1-Propanol produced in this manner is mainly used for manufacturing cosmetics, dental lotion and insecticides ${ }^{2}$.

$$
2 \mathrm{HC}=\mathrm{CH}_{2}+\mathrm{CO}+\mathrm{H}_{2} \rightarrow \mathrm{CH}_{3} \mathrm{CH}_{2} \mathrm{HC}=\mathrm{O}
$$$$
\mathrm{CH}_{3} \mathrm{CH}_{2} \mathrm{HC}=\mathrm{O}+\mathrm{H}_{2} \rightarrow \mathrm{CH}_{3} \mathrm{CH}_{2} \mathrm{CH}_{2} \mathrm{OH} \text { (2) }
$$

As the di- $n$-propyl ether/1-propanol binary system forms an azeotrope at $66.47 \mathrm{~mol} \%$ at atmospheric pressure, it is very difficult to separate them into high-purity components by using a single-distillation column. Typical procedures to separate azeotropic mixtures using more than 2 distillation columns are pressure swing distillation, azeotropic distillation and extraction distillation processes ${ }^{3}$. To perform computer simulations on these processes, the vapor-liquid phase equilibrium should be studied before hand. The database of physical properties in the PRO/II simulator with PROVISION $9.1^{4}$ software (a commercial chemical process simulator of Invensys, Inc.) is equipped with binary interaction parameters of thermodynamic model equations for the di- $n$-propyl ether/ 1-propanol binary system. In Fig. 1, the experimental data ${ }^{5}$ for the vapor-liquid phase equilibrium of the di- $n$-propyl ether/ 1- propanol system at atmospheric pressure are compared with the calculated values obtained by using the NRTL liquid activity coefficient model equation embedded in PRO/II with PROVISION 9.1. Unfortunately, the data embedded in the simulator leads to somewhat inconsistent results. Thus, in this study, vapor-liquid phase equilibrium experiments for the di$n$-propyl ether/1-propanol binary system were conducted at 1,013 and 300 mbar, respectively, to determine the exact coefficient parameters which fit in well with the experimental data. Experimental pressures were chosen as 1,013 mbar and 300 mbar of reduced pressure to match the operating pressure of a pressure swing distillation column. UNIQUAC, NRTL 
and Wilson equations of the LACT (liquid activity coefficients thermodynamics) model were used for the regression analysis of the vapor-liquid phase equilibrium and the accuracies among the model equations were compared ${ }^{6,7}$.

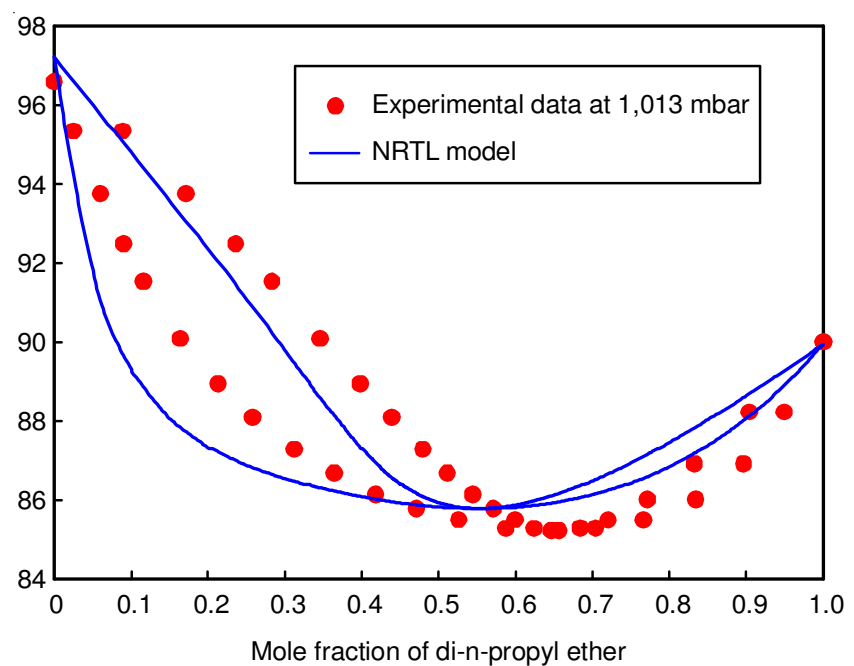

Fig. 1. Binary experimental data for di-n-propyl ether and 1-propanol at 1,013 mbar and its prediction

\section{EXPERIMENTAL}

Di- $n$-propyl ether (Tokyo Chemical Industry Co.) with a purity of higher than 98 wt.\% was used. 1-Propanol was obtained from the SIGMA-ALDRICH Co. with a purity greater than 99.9 wt.\%. By measuring the boiling points of the pure components, it was confirmed that di- $n$-propyl ether was boiling at $90.18{ }^{\circ} \mathrm{C}$ and 1-propanol at $97.30^{\circ} \mathrm{C}$. Accuracy in the temperature measurements was $\pm 0.02{ }^{\circ} \mathrm{C}$. Their boiling points and physical properties obtained from the literatures are shown in Table-1.

\begin{tabular}{lcc}
\multicolumn{3}{c}{ TABLE-1 } \\
\multicolumn{3}{c}{$\begin{array}{c}\text { PHYSICAL PROPERTY OF DI- } n \text {-PROPYL } \\
\text { ETHER AND 1-PROPANOL }\end{array}$} \\
\hline Property & Di- $n$-propyl ether & 1-Propanol \\
\hline Structure & $-\mathrm{O}$ & $\mathrm{C}^{\text {OH }}$ \\
Formula & $\mathrm{C}_{6} \mathrm{H}_{14} \mathrm{O}$ & $\mathrm{C}_{3} \mathrm{H}_{8} \mathrm{O}$ \\
Molecular weight & 102.17 & 60.10 \\
Density $\left(\mathrm{g} / \mathrm{cm}^{3}\right)$ & 0.75 & 0.80 \\
Melting point $\left({ }^{\circ} \mathrm{C}\right)$ & -122 & -126 \\
Boiling point $\left({ }^{\circ} \mathrm{C}\right)$ & 90 & $97-98$ \\
Experimental boiling point $\left({ }^{\circ} \mathrm{C}\right)$ & 90.18 & 97.30 \\
Flash point $\left({ }^{\circ} \mathrm{C}\right)$ & -18 & 15 \\
\hline
\end{tabular}

Procedure: Vapor-liquid phase equilibrium experiments were conducted using a VLE 602 apparatus (Fischer Engineering $\mathrm{GmbH}$ ), as shown in Fig. 2. Descriptions of its parts are summarized in Table-2. In this apparatus, heat was provided from the immersion heater (No. 1), which rapidly increased the temperature of the mixture and generated vapor while the liquid was circulating.

The system pressure can be adjusted in 0.01 mbar increments using a separate control box. The temperature of the system can be increased in $0.01{ }^{\circ} \mathrm{C}$ increments using a digital thermometer, which was installed at no. 8 and no. 9

\begin{tabular}{cc|cc}
\multicolumn{4}{c}{ TABLE-2 } \\
\multicolumn{4}{c}{ DETAILS OF THE VAPOR-LIQUID EQUILIBRIUM } \\
\hline No. & EXPERIMENTAL EQUIPMENT \\
\hline 1 & Name & No. & Name \\
2 & Cottrell-pump & 14 & Solenoid: vapor \\
3 & Separation chamber & 16 & Receiver: liquid \\
4 & Condenser & 17 & Receiver: vapor \\
5 & Cooler vapor phase & 18 & Valve \\
6 & Cooler liquid phase & 19 & Ventilation valve \\
7 & Mixing chamber & 20 & Ventilation valve \\
8 & Thermometer: vapor & 21 & Sample valve \\
9 & Thermometer: liquid & 22 & Sample valve \\
10 & Septum: liquid & 23 & Discharge valve \\
11 & Septum: vapor & 24 & Isolation tube \\
12 & Septum: vapor & 25 & Isolation jacket \\
13 & Solenoid: liquid & 26 & Connection to vessel \\
\hline
\end{tabular}

(Fig. 2). The thermometer can measure a wide temperature range varying between -200 and $845^{\circ} \mathrm{C}$ with an accuracy of \pm $0.02{ }^{\circ} \mathrm{C}$. In case of $1,013 \mathrm{mbar}$, experiments were carried out by opening valves no. 17, 18, 19 and 20 (Fig. 2) to ensure a passage way to the atmosphere. For low-pressure experiments, the pressure was controlled by using a vacuum pump installed separately. In this work, a vacuum was maintained between no. 15 and 16 in order to take samples by closing valves no. 19 and 20 and opening valves no. 17 and 18 (Fig. 2). In this study, experiments were performed after confirming that each set pressure was maintained for longer than $0.5 \mathrm{~h}$.

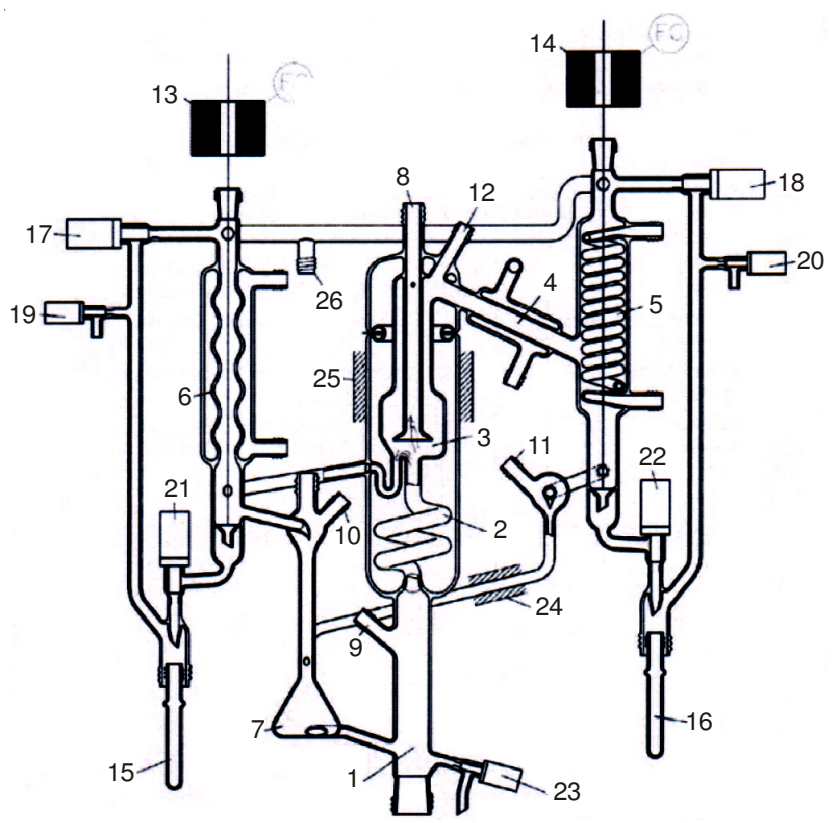

Fig. 2. Apparatus for vapor-liquid equilibrium experimental equipment

The samples obtained from experiments were analyzed by aYL6100 Gas chromatograph (GC, Younglin instrument Co., Ltd). A capillary column was installed to ensure facile high-concentration analysis. In addition, an autosampler of HT300A type was used for the GC analysis. The autosampler was useful in obtaining more accurate analysis results by controlling the sample feeding rate. The detailed conditions used in the GC analysis are represented in Table-3. 


\begin{tabular}{ll}
\hline $\begin{array}{c}\text { TABLE-3 } \\
\text { CONDITIONS FOR THE GAS CHROMATOGRAPHIC } \\
\text { ANALYSIS OF SAMPLE }\end{array}$ \\
\hline Contents & Setting values \\
\hline GC & YL $6100 \mathrm{GC}$ \\
Autosampler & HT300A \\
Carrier gas & Helium, $1.3 \mathrm{~mL} / \mathrm{min}$ \\
Column & Carbowax capillary \\
& $(30 \mathrm{~m} \times 0.32 \mathrm{~mm} \times 0.25 \mu \mathrm{m})$ \\
Injector & Temperature $200{ }^{\circ} \mathrm{C}$ \\
& Flow rate $5 \mathrm{~mL} / \mathrm{min}$ \\
& Split ratio $100: 1$ \\
& Split flow $495.0 \mathrm{~mL} / \mathrm{min}$ \\
& Total flow $503.0 \mathrm{~mL} / \mathrm{min}$ \\
& Pressure: $5.1 \mathrm{psi}$ \\
& Initial: $60^{\circ} \mathrm{C}, 2 \mathrm{~min}$ hold \\
& Flame ionization detector (FID) \\
Oven & Temperature: $230^{\circ} \mathrm{C}$ \\
Detector & $\mathrm{H}_{2}: 30 \mathrm{~mL} / \mathrm{min}$ \\
& Air: $300 \mathrm{~mL} / \mathrm{min}$ \\
\hline
\end{tabular}

Calibration curve preparation: It is essential to prepare a calibration curve for the concentration analysis of samples obtained from vapor-liquid phase equilibrium experiments. In this study, GC analysis was performed using a total of 11 standard samples prepared based on the weight percentage of di- $n$-propyl ether. Weights and weight percentages of di- $n$ propyl ether measured during standard sample preparation are shown in Table-4.

\begin{tabular}{cccc}
\multicolumn{4}{c}{ TABLE-4 } \\
\multicolumn{4}{c}{ CALCULATED WEIGHT PERCENTAGES } \\
OF DI- $n$-PROPYL ETHER \\
\hline No. & Weight of di- $n$-propyl ether $(\mathrm{g})$ & Total weight $(\mathrm{g})$ & wt. $\%$ \\
\hline 1 & 1.97 & 20.00 & 9.85 \\
2 & 3.93 & 20.01 & 19.64 \\
3 & 5.88 & 20.00 & 29.40 \\
4 & 7.84 & 20.00 & 39.20 \\
5 & 9.80 & 20.01 & 48.98 \\
6 & 11.76 & 20.00 & 58.80 \\
7 & 13.72 & 20.08 & 68.33 \\
8 & 15.68 & 20.01 & 78.36 \\
9 & 17.64 & 20.00 & 88.20 \\
\hline
\end{tabular}

For highly accurate calibration curve preparation, GC analysis was carried out five times at each standard sample concentration; calibration curves and their equations are shown in Fig. 3 and Table-5. The $\mathrm{x}$-axis of Fig. 3 is an area ratio of di- $n$-propyl ether based on the total area measured from GC analysis as $100 \%$, while the y-axis corresponds to the real weight percentage of di-n-propyl ether. Our result has high accuracy because the value of the correlation coefficient $\left(\mathrm{R}^{2}\right)$ of the calibration curve was calculated to be greater than 0.999 .

\section{RESULTS AND DISCUSSION}

Vapor-liquid phase equilibrium experiments at 1,013 mbar: In this study, vapor and liquid samples were collected 21 times during the vapor-liquid phase equilibrium experiments at 1,013 mbar. The samples collected were analyzed three times per sample using GC and an arithmetic average of the calculated area ratios was taken. The weight concentration based of di- $n$-propyl ether was calculated by applying the arithmetic average value to the calibration curve.

\begin{tabular}{|c|c|c|}
\hline \multicolumn{3}{|c|}{$\begin{array}{c}\text { TABLE-5 } \\
\text { PHYSICAL PROPERTY OF DI- } n \text {-PROPYL } \\
\text { ETHER AND 1-PROPANOL }\end{array}$} \\
\hline Component & Equation & $\mathrm{R}^{2}$ \\
\hline Di-n-propyl ether & $y=0.0026 x^{2}+0.7477 x$ & 0.9996 \\
\hline $\begin{array}{l}x \text {. Area ratio of di- } n \\
y \text {. Real weight perce }\end{array}$ & $\begin{array}{l}\text { ether, } \\
\text { i- } n \text {-propyl ether }\end{array}$ & \\
\hline
\end{tabular}

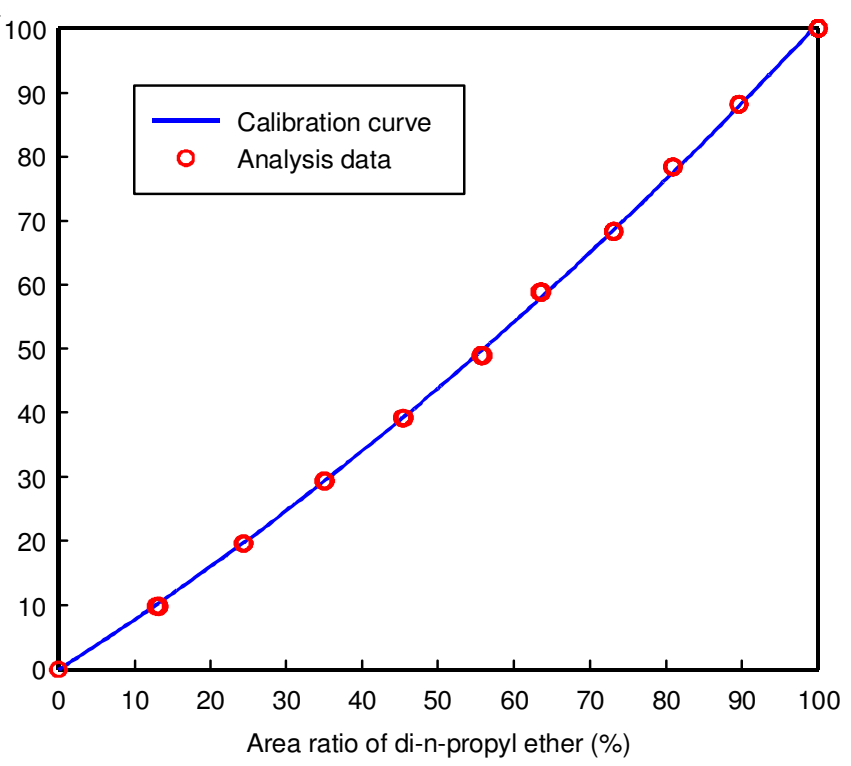

Fig. 3. Calibration curve for the experimental results

The weight concentrations were converted to mole concentrations by using calculated weight concentrations and the molecular weight of each component. The experimental results at 1,013 mbar are shown in Table-6 and TXY phase equilibrium experimental data of the di- $n$-propyl ether/1-propanol binary system are shown in Fig. 4.

\begin{tabular}{|c|c|c|c|}
\hline \multicolumn{4}{|c|}{$\begin{array}{c}\text { TABLE-6 } \\
\text { EXPERIMENTAL VAPOR-LIQUID EQUILIBRIUM } \\
\text { DATA FOR THE DI- } n \text {-PROPYL ETHER (1) AND } \\
\text { 1-PROPANOL (2) SYSTEM AT 1,013 mbar }\end{array}$} \\
\hline No. & Temperature $\left({ }^{\circ} \mathrm{C}\right)$ & $\mathrm{x}_{1}$ & $\mathrm{y}_{1}$ \\
\hline 1 & 97.30 & 0.0000 & 0.0000 \\
\hline 2 & 97.14 & 0.0032 & 0.0090 \\
\hline 3 & 96.50 & 0.0120 & 0.0354 \\
\hline 4 & 95.89 & 0.0229 & 0.0664 \\
\hline 5 & 95.06 & 0.0363 & 0.1020 \\
\hline 6 & 94.42 & 0.0462 & 0.1314 \\
\hline 7 & 93.43 & 0.0672 & 0.1799 \\
\hline 8 & 92.56 & 0.0874 & 0.2150 \\
\hline 9 & 91.13 & 0.1248 & 0.2895 \\
\hline 10 & 89.89 & 0.1681 & 0.3432 \\
\hline 11 & 89.08 & 0.2007 & 0.3784 \\
\hline 12 & 86.88 & 0.3350 & 0.4815 \\
\hline 13 & 85.74 & 0.5035 & 0.5765 \\
\hline 14 & 85.62 & 0.5258 & 0.5957 \\
\hline 15 & 85.54 & 0.5618 & 0.6069 \\
\hline 16 & 85.46 & 0.5953 & 0.6257 \\
\hline 17 & 85.44 & 0.6645 & 0.6544 \\
\hline 18 & 85.72 & 0.7986 & 0.7398 \\
\hline 19 & 87.15 & 0.9066 & 0.8475 \\
\hline 20 & 88.93 & 0.9693 & 0.9334 \\
\hline 21 & 90.18 & 1.0000 & 1.0000 \\
\hline
\end{tabular}




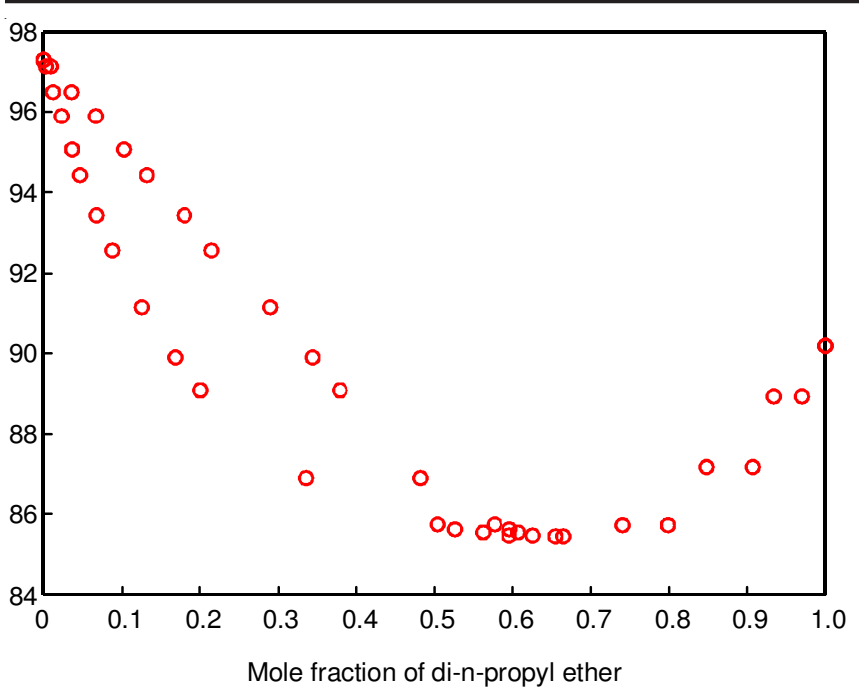

Fig. 4. TXY plot for experimental VLE data at 1,013 mbar

Studies have been carried out on the vapor-liquid phase equilibrium experiments in the di- $n$-propyl ether/1-propanol binary system at atmospheric pressure ${ }^{8}$. Furthermore, accurate literature data for boiling points of their pure components also exist. The results obtained from these experiments were compared with those of the preceding work in Table-7. It was demonstrated during the course of this work that the experimental results in this study are similar to those of the preceding work in terms of azeotropic composition and temperature. In addition, the boiling points of pure components showed less deviation than those of the previous work. Thus, it was confirmed that this study exhibited a relatively high level of accuracy.

\begin{tabular}{|c|c|c|c|}
\hline \multicolumn{4}{|c|}{$\begin{array}{c}\text { TABLE-7 } \\
\text { COMPARISON OF EXPERIMENTAL DATA AT } \\
1,013 \text { MBAR WITH PRESENT AND PREVIOUS DATA }\end{array}$} \\
\hline Contents & $\begin{array}{l}\text { Present } \\
\text { data }\end{array}$ & $\begin{array}{l}\text { Previous } \\
\text { data }\end{array}$ & $\begin{array}{c}\text { Experimental } \\
\text { data }\end{array}$ \\
\hline $\begin{array}{l}\text { Boiling point of 1-propanol } \\
\left({ }^{\circ} \mathrm{C}\right)\end{array}$ & 97.22 & 96.60 & 97.30 \\
\hline Azeotropic temperature $\left({ }^{\circ} \mathrm{C}\right)$ & - & 85.16 & 85.45 \\
\hline Azeotropic composition & - & 0.6647 & 0.6472 \\
\hline $\begin{array}{l}\text { Boiling point of di- } n \text {-propyl } \\
\text { ether }\left({ }^{\circ} \mathrm{C}\right)\end{array}$ & 90.08 & 90.01 & 90.18 \\
\hline
\end{tabular}

Vapor-liquid phase equilibrium experiments at $\mathbf{3 0 0}$ mbar: Based on the experimental findings at 1,013 mbar, a set of experiments were carried out at a low pressure of 300 mbar. Analogous to the experiments at atmospheric pressure, vapor and liquid samples were collected 21 times and the GC analysis was performed three times per sample. The experimental results at 300 mbar are shown in Table- 8 and TXY phase equili-brium experimental data of di- $n$-propyl ether/1-propanol binary system are shown in Fig. 5.

The experimental results determined that the azeotropic composition at 300 mbar was 0.7682 and the azeotropic temperature was $52.61^{\circ} \mathrm{C}$. By comparing theses results with the results at 1,013 mbar, it was found that the azeotropic temperature decreased and the azeotropic composition increased when the system pressure was decreased. Accordingly, it was identified that the azeotropic point of di- $n$-propyl ether/ 1-propanol binary pair changes according to the pressure level.

\begin{tabular}{cccc}
\hline \multicolumn{4}{c}{ TABLE-8 } \\
\multicolumn{4}{c}{ EXPERIMENTAL VAPOR-LIQUID EQUILIBRIUM } \\
\multicolumn{4}{c}{ DATA FOR THE DI- $n$-PROPYL ETHER (1) AND } \\
\hline 1-PROPANOL $(2)$ SYSTEM AT 300 MBAR \\
\hline 1 & Temperature $\left({ }^{\circ}\right.$ C) & $\mathrm{x}_{1}$ & $\mathrm{y}_{1}$ \\
\hline 2 & 68.45 & 0.0000 & 0.0000 \\
3 & 68.36 & 0.0031 & 0.0096 \\
4 & 66.38 & 0.0226 & 0.0964 \\
5 & 63.91 & 0.0529 & 0.2134 \\
6 & 61.75 & 0.0888 & 0.3133 \\
7 & 60.80 & 0.1075 & 0.3596 \\
8 & 58.94 & 0.1527 & 0.4438 \\
9 & 56.93 & 0.2195 & 0.5319 \\
10 & 55.58 & 0.2978 & 0.5883 \\
11 & 54.88 & 0.3473 & 0.6167 \\
12 & 54.35 & 0.3892 & 0.6377 \\
13 & 53.89 & 0.4344 & 0.6595 \\
14 & 53.32 & 0.5151 & 0.6873 \\
15 & 52.93 & 0.5951 & 0.7126 \\
16 & 52.79 & 0.6319 & 0.7245 \\
17 & 52.73 & 0.6636 & 0.7362 \\
18 & 52.63 & 0.7201 & 0.7561 \\
19 & 52.60 & 0.8145 & 0.7798 \\
20 & 52.72 & 0.8859 & 0.8299 \\
21 & 53.28 & 0.9463 & 0.9032 \\
& 54.54 & 1.0000 & 1.0000 \\
\hline
\end{tabular}

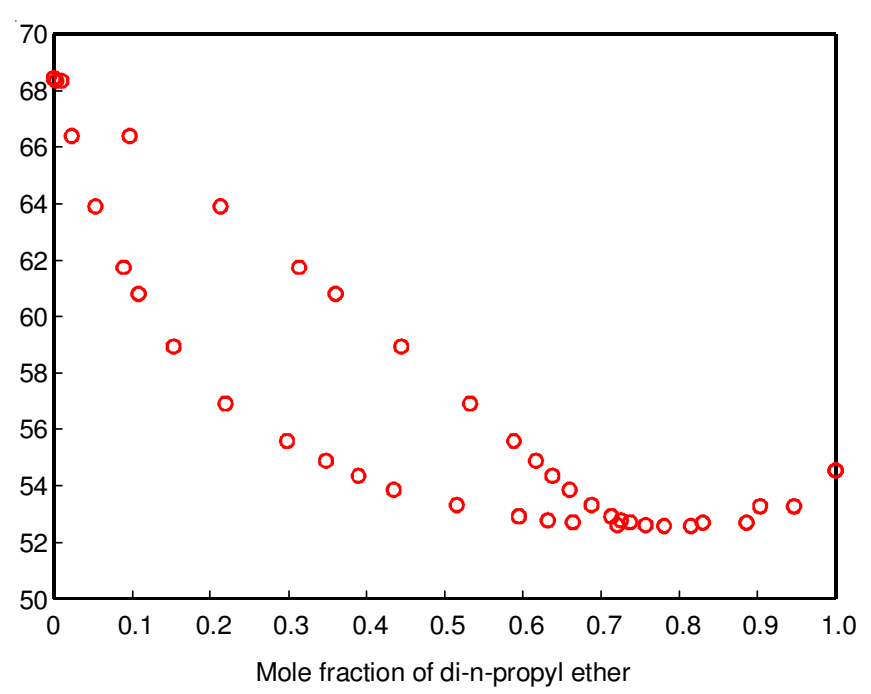

Fig. 5. TXY plot for experimental VLE data at $300 \mathrm{mbar}$

Thermodynamic data regression: In this study, the commercial chemical process simulator PRO/II with the PROVISION 9.1 program was utilized for the regression analysis of the experimental data. Liquid activity coefficient models such as UNIQUAC, NRTL and Wilson equations were adopted for the analysis. In PRO/II with PROVISION 9.1, binary interaction parameters for each LACT model are built-in, as shown in Table-9. Unfortunately, the embedded parameters led to poor vapor-liquid phase equilibrium calculations. A significant deviation between the results calculated from the built-in parameters and the experimental data obtained in this study was revealed, as shown in Fig. 6.

By performing the regression analysis using vapor-liquid phase equilibrium experimental data produced at 1,013 and 300 mbar, the binary interaction parameters of thermodynamic model equations were determined. The optimized parameters were obtained in such a way to minimize the object function 


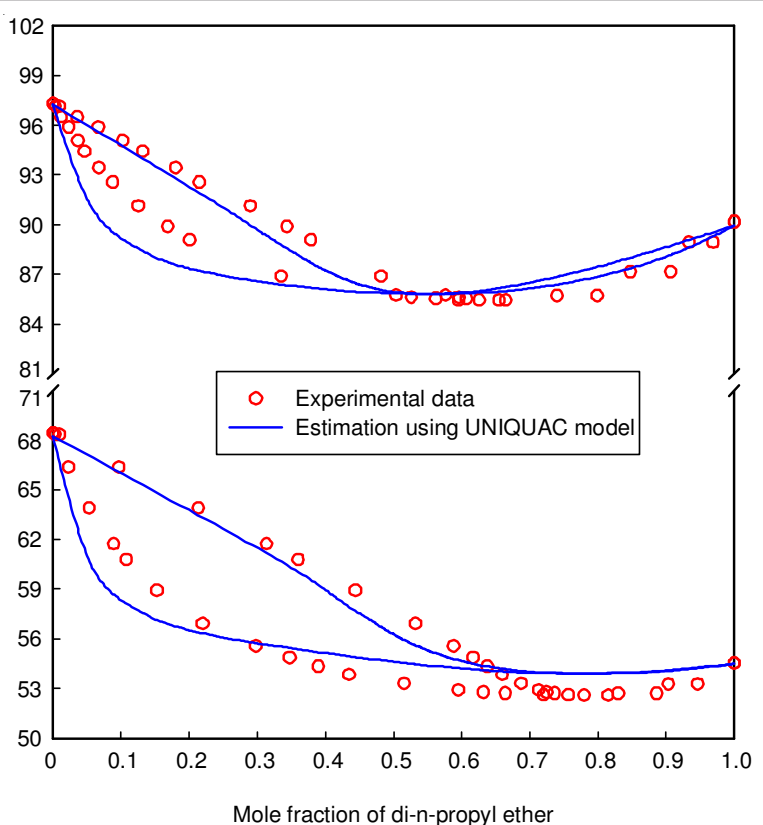

Fig. 6. Comparison of experimental data with calculated data using existing UNIQUAC parameter

TABLE-9

BINARY PARAMETERS BUILT IN PRO/II FOR DI- $n$-PROPYL ETHER(1) AND 1-PROPANOL(2) SYSTEM

\begin{tabular}{cc}
\hline Thermodynamic model & Parameters built in PRO/II \\
\hline \multirow{2}{*}{ UNIQUAC } & $\mathrm{A}_{12}=-21.0865$ \\
& $\mathrm{~A}_{21}=200.4666$ \\
\hline \multirow{2}{*}{ NRTL } & $\mathrm{B}_{12}=-114.0849$ \\
& $\mathrm{~B}_{21}=769.8521$ \\
$\alpha_{12}=0.3$ \\
\hline \multirow{2}{*}{ WILSON } & $A_{12}=670.4239$ \\
& $A_{21}=189.7614$ \\
\hline
\end{tabular}

(OF) defined in eqn. 3 as a form of relative deviation between the experimental $\mathrm{K}$-values and the calculated $\mathrm{K}$-values.

$$
\text { Object function }(\mathrm{OF})=\sum_{\mathrm{i}=1}^{2} \sum_{\mathrm{j}=1}^{\mathrm{N}}\left[\frac{\mathrm{K}_{\mathrm{i}, \mathrm{j} \text {,exp }}-\mathrm{K}_{\mathrm{i}, \mathrm{j}, \mathrm{cal}}}{\mathrm{K}_{\mathrm{i}, \mathrm{j} \text { exp }}}\right]^{2}
$$

The binary parameters of each model obtained from the regression analysis are presented in Table-10. In addition, the azeotropic composition and temperature of each model were calculated through flash calculation using PRO/II; their results are summarized in Table- 11 along with the experimental results. The UNIQUAC model is shown to estimate the azeotropic composition and temperature that are similar to the experimental results.

\begin{tabular}{|c|c|}
\hline \multicolumn{2}{|c|}{$\begin{array}{c}\text { TABLE-10 } \\
\text { REGRESSED BINARY PARAMETERS FOR DI- } n \text {-PROPYL } \\
\text { ETHER(1) AND 1-PROPANOL(2) SYSTEM } \\
\end{array}$} \\
\hline Thermodynamic model & Regressed binary parameters \\
\hline UNIQUAC & $\begin{array}{l}A_{12}=886.1091 \\
A_{21}=-353.618 \\
B_{12}=-1.76182 \\
B_{21}=0.784816\end{array}$ \\
\hline NRTL & $\begin{aligned} \mathrm{B}_{12} & =301.4776 \\
\mathrm{~B}_{21} & =152.3047 \\
\alpha_{12} & =0.3\end{aligned}$ \\
\hline WILSON & $\begin{array}{c}A_{12}=-12.0442 \\
A_{21}=503.022\end{array}$ \\
\hline
\end{tabular}

\begin{tabular}{cccc}
\hline \multicolumn{5}{c}{ TABLE-11 } \\
AZEOTROPIC TEMPERATURE AND MOLE \\
COMPOSITION OF DI- $n$-PROPYL ETHER \\
\hline $\begin{array}{c}\text { Pressure } \\
\text { (mbar) }\end{array}$ & $\begin{array}{c}\text { Thermodynamic } \\
\text { model }\end{array}$ & $\begin{array}{c}\text { Azeotropic } \\
\text { temp. }\left({ }^{\circ} \mathrm{C}\right)\end{array}$ & $\begin{array}{c}\text { Azeotropic } \\
\text { comp. }\end{array}$ \\
\hline \multirow{4}{*}{1,013} & Experimental & 85.45 & 0.6472 \\
& UNIQUAC & 85.53 & 0.6496 \\
& NRTL & 85.15 & 0.6569 \\
& WILSON & 85.16 & 0.6573 \\
\hline \multirow{5}{*}{300} & Experimental & 52.61 & 0.7682 \\
& UNIQUAC & 52.58 & 0.7813 \\
& NRTL & 52.79 & 0.7843 \\
& WILSON & 52.80 & 0.7917 \\
\hline
\end{tabular}

For a more precise comparison, RMSD (root mean square deviation) and AAD \% (average absolute deviation \%) were calculated by using the experimental and calculated data. RMSD and AAD \% are defined as in eqn. 4 and 5, respectively, where $\mathrm{N}$ and $\mathrm{y}_{\mathrm{i}}$ represents the number of data and vapor mole fraction of component $i$. Results of RMSD and AAD \% are summarized in Tables 12 and 13, respectively along with their existing embedded parameters.

$$
\begin{aligned}
& \operatorname{RMSD}=\sqrt{\frac{1}{N} \sum\left(y_{i}^{\text {exp }}-y_{i}^{c a l}\right)^{2}} \\
& \operatorname{AAD} \%=\frac{100}{N}\left|y_{i}^{\text {exp }}-y_{i}^{\text {cal }}\right|
\end{aligned}
$$

\begin{tabular}{cccc}
\multicolumn{4}{c}{ TABLE-12 } \\
& RESULTS OF RMSD CALCULATION & \\
\hline $\begin{array}{c}\text { Pressure } \\
\text { (mbar) }\end{array}$ & Thermodynamic & RMSD & RMSD \\
model & (Existing) & $($ New $)$ \\
\hline \multirow{2}{*}{1,013} & UNIQUAC & 0.06369 & 0.00877 \\
& NRTL & 0.06111 & 0.01171 \\
& WILSON & 0.07651 & 0.01218 \\
\hline \multirow{3}{*}{300} & UNIQUAC & 0.08165 & 0.00858 \\
& NRTL & 0.08009 & 0.01433 \\
& WILSON & 0.09200 & 0.02878 \\
\hline
\end{tabular}

\begin{tabular}{cccc}
\multicolumn{5}{c}{ TABLE-13 } \\
RESULTS OF AAD \% CALCULATION \\
\hline $\begin{array}{c}\text { Pressure } \\
\text { (mbar) }\end{array}$ & $\begin{array}{c}\text { Thermodynamic } \\
\text { model }\end{array}$ & $\begin{array}{c}\text { AAD \% } \\
\text { (Existing) }\end{array}$ & $\begin{array}{c}\text { AAD \% } \\
\text { (New) }\end{array}$ \\
\hline \multirow{3}{*}{1,013} & UNIQUAC & 5.137 & 0.748 \\
& NRTL & 4.969 & 0.997 \\
& WILSON & 5.923 & 0.873 \\
\hline \multirow{3}{*}{300} & UNIQUAC & 6.690 & 0.621 \\
& NRTL & 6.662 & 1.233 \\
& WILSON & 7.374 & 2.134 \\
\hline
\end{tabular}

It was clear that the accuracy of the calculated results was significantly enhanced when new parameters were used instead of the existing built-in parameters. Similar to the instance of the calculation of azeotropic composition and temperature, the UNIQUAC model also exhibited the smallest RMSD and AAD \% values with the experimental results. The calculated results obtained using new parameters of the UNIQUAC model are compared with the experimental results in Fig. 7.

\section{Conclusion}

Herein, vapor-liquid phase equilibrium experiments for the di- $n$-propyl ether/1-propanol binary system were carried out at 1,013 and 300 mbar, respectively. The results showed 


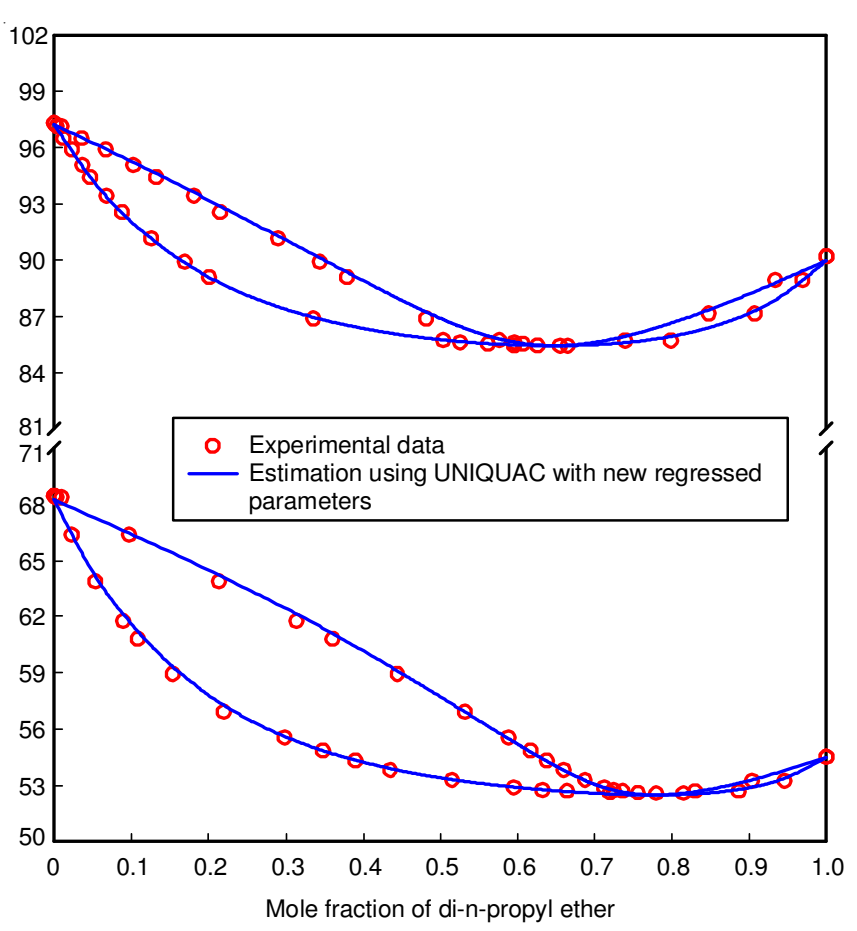

Fig. 7. Comparison of experimental data with calculated data using new parameters regressed by UNIQUAC model

that the azeotropic composition increased from 0.6472 to 0.7682 when the system pressure was reduced from 1,013 to 300 mbar. By performing regression analysis of the experimental results at atmospheric pressure and lower pressure, the interaction parameters of UNIQUAC, NRTL and WILSON models (based on the LACT method) were obtained. By calculating the vapor-liquid phase equilibrium using the new sets of parameters, higher accuracy results could be obtained compared with those using the parameters embedded in the PRO/II simulator. It was found that the UNIQUAC model provides the highest accuracy among various LACT models.

More accurate results can be obtained if the new interaction parameters achieved from this study are applied in the simulation of the di- $n$-propyl ether/1-propanol binary system. It would be very useful to obtain parameters of high accuracy by extending the application of the methodology reported here to other various binary systems.

\section{ACKNOWLEDGEMENTS}

This research was supported by a grant from LNG Plant R\&D Center founded by Ministry of Land, Transportation and Maritime affairs (MLTM) of the Korean government.

\section{REFERENCES}

1. J.P. Knapp and M.F. Doherty, Ind. Eng. Chem. Res., 31, 346 (1992).

2. W.F. Furter, Chem. Eng. Commun., 116, 35 (1992).

3. P. Kaul and R. Thrasher, SPE Reserv. Eng., 11, 273 (1996).

4. G.M. Kontogeorgis, A. Fredenslund and D.P. Tassios, Ind. Eng. Chem. Res., 32, 362 (1993).

5. T. Anderson and J. Prausnitz, Ind. Eng. Chem. Process Des. Dev., 17, 552 (1978).

6. H. Renon and J. Prausnitz, Ind. Eng. Chem. Process Des. Dev., 8, 413 (1969).

7. R. Orye and J. Prausnitz, Ind. Eng. Chem., 57, 18 (1965).

8. E. Lladosa, J.B. Montón, M.C. Burguet and R. Muñoz, Fluid Phase Equilib., 247, 47 (2006). 